\title{
0 debate sobre educação em saúde no âmbito do Conselho Municipal de Saúde de Vitória, ES, Brasil
}

Welington Serra Lazarini(a)

Francis Sodré(b)

Maristela Dalbello-Araujo(c)

Lazarini WS, Sodré F, Dalbello-Araujo M. The debate on health education in the scope of the Municipal Health Council of Vitória, Southeastern Brazil. Interface (Botucatu). 2014;18 Supl 2:1227-1240.

We analyzed the relationship between health education and the politics of participation and social control in health of the Municipal Health Department of Vitória, from 2005 to 2012. A documental analysis was performed in the Municipal Health Plans, Management Reports and in 139 proceedings of the Municipal Health Council $(\mathrm{MHC})$. The results showed that the management guided its politics according to participation, but restricted itself to the MHC. Health education was partially treated during the meetings. When it was debated, it was as the traditional model, being configured as a strategy for population surveillance. Popular Health Education was mentioned only in the second term, but it was not accompanied by a redefinition of practices. The conclusion is that it is necessary to recognize different forms of social participation in Vitória and to further discuss the dialogic model of health education.

Keywords: Health education. Social participation. Health Council.
Analisou-se a relação entre educação em saúde e a política de participação e controle social em saúde da Secretaria Municipal de Saúde de Vitória-ES, Brasil, entre 2005 e 2012. Realizou-se análise documental nos planos municipais de saúde, relatórios de gestão e em 139 atas do Conselho Municipal de Saúde. Evidenciou-se que a gestão orientou sua política pela participação, mas restringiu-se ao Conselho Municipal de Saúde. A educação em saúde foi tratada pontualmente durante as reuniões. Quando debatida, foi como modelo tradicional, configurando-se em estratégia para vigilância. A Educação Popular em Saúde foi mencionada no segundo governo, mas sem a redefinição das práticas. Sinaliza-se a necessidade de reconhecer as diferentes formas de participação social em Vitória e ampliar o debate acerca do modelo dialógico da educação em saúde.

Palavras-chave: Educação em saúde. Participação social. Conselho de Saúde.

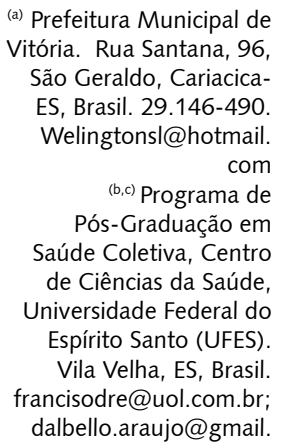

(a) Prefeitura Municipal de Vitória. Rua Santana, 96, São Geraldo, CariacicaES, Brasil. 29.146-490. Welingtonsl@hotmail.

$(b, c)$ Programa de Pós-Graduação em Saúde Coletiva, Centro de Ciências da Saúde, Universidade Federal do Espírito Santo (UFES) Vila Velha, ES, Brasil. francisodre@uol.com.br; dalbello.araujo@gmail. 


\section{Introdução}

Os conselhos de saúde se configuram em um dos principais mecanismos de participação institucionalizada do Sistema Único de Saúde (SUS) ${ }^{1}$. Sua dinâmica representativa envolve diversos atores e traz, para a agenda de debates, temas importantes que afetam as relações entre o Estado e a sociedade, como é o caso da educação em saúde produzida nos serviços.

Desse modo, esse artigo tem por objetivo analisar a relação entre a educação em saúde e a política de participação e controle social promovida na cidade de Vitória-ES, no período compreendido entre 2005 a 2012. O foco da pesquisa dirige-se à frequência na qual as práticas educativas são discutidas nas reuniões do Conselho Municipal de Saúde, sua forma de apresentação e as principais concepções que caracterizam a práxis dessas ações.

Embora esteja posto que a educação em saúde, no âmbito dos serviços, seja essencial para a melhoria da saúde individual e coletiva, nem sempre suas práticas são conduzidas de maneira satisfatória, uma vez que a diversidade de objetivos e metodologias, que são postas no cotidiano, não favorecem a promoção de uma ação compartilhada de saberes, calcada no diálogo².

Vários estudos ${ }^{3-6}$ apontam para a fragilidade dessas ações, em parte pelo descaso que as instituições do SUS vêm tratando o tema. Assim, a postura política contida nessas concepções revelam determinados interesses e incidem sobre os diferentes arranjos de poder que envolvem o homem e a sociedade ${ }^{7}$.

Em virtude do seu caráter polissêmico, compreende-se a educação em saúde como um conjunto de saberes e práticas diversas, que se estabelecem no encontro entre os trabalhadores da saúde e a população, no âmbito individual ou coletivo. Essa interação pode ocorrer tanto no interior dos serviços quanto na comunidade, de maneira formal ou não, cujo propósito visa a um modelo dialógico "que favorece o reconhecimento dos usuários como sujeitos portadores de saberes sobre o processo saúdedoença-cuidado e de condições concretas de vida"4 (p. 50).

Nesse sentido, o esforço de tornar a educação em saúde uma prática central para o processo de produção de saúde, entendida como estratégia mediante o processo de construção da autonomia dos sujeitos e coletividades, passa pela necessidade de politização da sociedade brasileira, sobretudo no que tange ao debate acerca da importância da participação social na saúde.

Ao longo do século XX, entretanto, as práticas educativas foram conduzidas pelo Estado com o objetivo central de atender aos interesses políticos e econômicos das elites. Até a década de 1970, essas ações eram orientadas pela unilateralidade, ou seja, pautavam-se pela imposição de normas, sem exercer qualquer atitude crítica acerca do contexto sociopolítico ${ }^{8}$.

Contrariando o regime repressor instalado no período, começaram a surgir novas experiências de educação em saúde justamente durante o governo militar, cuja lógica orientadora era inversa a das práticas hegemônicas. Esse novo método recebeu a influência da obra de Paulo Freire e deu origem a Educação Popular em Saúde, que ganhou força com o Movimento Sanitário.

A Carta de Ottawa, lançada em 1986, considerou a educação em saúde como uma das estratégias básicas para a promoção da saúde em sua proposta teórica e política. Destaca em sua diretriz a necessidade de realizar uma prática desvinculada da doença e que tenha um caráter participativo, construtivista e transversal².

Com a criação do SUS no Brasil, estruturado a partir dos pilares democráticos da universalidade, equidade e da integralidade, fez-se necessário a reorientação do modelo assistencial vigente, que primava pela dicotomia entre assistência e prevenção4.

Ao começar a ser produzida por essa nova tendência, a educação em saúde passou a ser apontada como uma importante estratégia de mudança na sociedade. Contribuiu para fermentar as lutas sociais, não apenas para defender questões relativas às condições estritas de saúde, mas também para proporcionar a garantia de um debate amplo acerca do respeito à conquista da cidadania, de modo a observar todos os fatores que impactam diretamente na vida dos indivíduos como, entre outros, moradia, cultura, lazer, trabalho e educação 9 .

Para que essa realidade se torne possível, a participação da comunidade adquire fundamental importância. Definida na Lei $n^{\circ} 8.142 / 90$, essa diretriz tem tido papel relevante na luta pela efetivação do SUS, pois adquire um sentido de participação política. Exemplo disso são as decisões tomadas pelos conselhos municipais sobre a política de saúde ${ }^{10}$. 
Os conselhos de saúde são espaços deliberativos que compõem o arcabouço da máquina políticoinstitucional do SUS, configurando uma importante inovação do processo de democratização das decisões setoriais ${ }^{11}$. Todavia, sua prática concreta é marcada por um processo paradoxal, que mescla conquista e imposição. Tal situação ocorre, pois, embora tenham sido legalmente estabelecidos a partir de um processo de luta política, muitos conselhos municipais de saúde são instituídos meramente como obrigação legal ou iniciativas isoladas de alguns gestores ${ }^{10}$.

Nesse sentido, o texto discorre sobre as características do debate acerca da educação em saúde, ocorrido nas reuniões do Conselho Municipal de Saúde de Vitória-ES - espaço este entendido como instância institucionalizada da participação e do controle social em saúde ${ }^{12}$.

\section{Percurso metodológico}

O campo da educação em saúde tem fundado suas bases de produção de conhecimento por intermédio de metodologias qualitativas. Os debates teóricos que embasam os mais diversos modos de se operacionalizar essas práticas são frutos de análises qualitativas ${ }^{3}$.

Segundo Minayo"13, tal método "se aplica ao estudo da história, das relações, das representações, das crenças, das percepções e das opiniões, produtos das interpretações que os humanos fazem a respeito de como vivem, constroem seus artefatos e a si mesmos, sentem e pensam" (p. 57).

Este estudo teve como cenário a cidade de Vitória-ES, cuja organização compreende seis regiões de saúde, onde estão inseridas 28 unidades de saúde. Além disso, a rede de saúde conta ainda com dez centros de referências, dois pronto atendimentos, um laboratório central municipal, serviço de vigilância sanitária e orientação ao Exercício ${ }^{14}$.

A técnica empregada para a coleta de dados foi a pesquisa documental. Tal escolha parte da premissa que ela "permite identificar informações factuais nos documentos a partir de questões ou hipóteses de interesse" ${ }^{15}$ ( $p .38$ ). Além disso, torna-se possível fazer inferências sobre questões específicas acerca de determinados problemas de pesquisa.

Uma minuciosa investigação foi realizada nos planos municipais de saúde 2006-2009 e 2010-2013, nos relatórios de gestão dos anos de 2006, 2007, 2008, 2009 e em 139 atas produzidas pelo Conselho Municipal de Saúde entre 2005 e 2012, referentes a 91 reuniões ordinárias e 48 oriundas de reuniões extraordinárias. Esses documentos são compreendidos como relevantes para a educação em saúde de Vitória, já que foram elaborados pela própria Secretaria Municipal de Saúde e discorrem sobre seus planos e metas, bem como suas realizações e dificuldades. Em relação às atas produzidas pelo conselho, particularmente, são consideradas como fontes passíveis de investigação acerca das concepções dos conselheiros municipais sobre as práticas educativas em saúde.

A escolha do período justifica-se pelo interesse em compreender o modo como as práticas de educação em saúde foram pautadas nos debates do conselho municipal de saúde de Vitória-ES, em duas gestões consecutivas de governos com ordenação de centro-esquerda, que possuem como uma de suas prerrogativas a participação popular. O primeiro governo (2005-2008) foi conduzido pela coligação Movimento Vitória de todas as Cores, formada pelos partidos PT/PSB/PDT/PC do B/PHS/ PAN/PV. Já o segundo (2009-2012) pela coligação Todos Por Vitória, formado pelo PT/PMDB.

Durante o processo de pré-análise, as atas do Conselho Municipal de Saúde foram lidas e a exploração do material ocorreu mediante a busca do termo evocador "educ". Na primeira etapa, os trechos que continham o termo foram selecionados para posterior análise.

A fim de identificar os temas, as relações e as contradições pertinentes ao entendimento das práticas de educação em saúde, a presente pesquisa procedeu à análise qualitativa dos dados. Desse modo, como estratégia metodológica foi utilizada a análise de conteúdo, definida por Bardin ${ }^{16}$ como:

Um conjunto de técnicas de análise das comunicações visando obter, por procedimentos, sistemáticos e objetivos de descrição do conteúdo das mensagens, indicadores (quantitativos ou não) que permitam a inferência de conhecimentos relativos às condições de produção/recepção (variáveis inferidas) destas mensagens. ${ }^{16}$ (p. 42) 
Esse método permite encontrar significados profundos presentes no campo das comunicações, subjacentes à superfície da mensagem emitida ${ }^{17}$, ou ainda, "produzir inferências de um texto para seu contexto social de maneira objetivada"18 (p. 191).

A construção das categorias respeitou as diretrizes metodológicas da análise de conteúdo temático, uma vez que esse é o método de análise geralmente utilizado para pesquisas documentais ${ }^{15,16}$. Sua formulação se deu com base nos sentidos presentes nas frases ou parágrafos, nos quais estavam inseridos o termo evocador.

As categorias foram analisadas à luz do conceito foucaultiano de biopoder, que discorre sobre a concepção de um poder que se constitui na articulação entre a tecnologia disciplinar, aplicada sobre os corpos dos indivíduos, e a biopolítica, dirigida à regulamentação da população, como poder de gestão e maximização da vida ${ }^{19}$.

No que concerne aos procedimentos éticos, a presente pesquisa foi aprovada pelo Comitê de Ética em Pesquisa do Centro de Ciências da Saúde da Universidade Federal do Espírito Santo, pela Coordenação de Pesquisas da Prefeitura de Vitória e pela Secretaria Municipal de Saúde.

A fim de sistematizar a crítica aos dados desta pesquisa, estruturou-se três categorias de análise que serão detalhadas a seguir, a saber: A política de participação e controle social da Semus, educação em saúde, como recurso para vigilância da população, e, por fim, educação popular em saúde na gestão municipal: estratégia de gestão participativa ou nova forma de controle?

\section{A política municipal de participação e controle social}

Os documentos oficiais analisados evidenciaram a opção por uma gestão participativa e democrática em ambos os governos, diferentemente dos modelos liberais anteriores. Especificamente nos planos municipais de saúde, formulados no primeiro ano de cada administração, e nos relatórios de gestão, produzidos anualmente, a participação cidadã e o controle social estão elencados entre os valores que orientam e servem de sustentação à política municipal de saúde.

A estratégia de gestão definida nesta administração é de um planejamento democrático e participativo, colegiado, sistemático e contínuo, integrado, baseado na intersetorialidade e na participação popular, partindo-se da democratização interna, no âmbito da Prefeitura e externa, da sociedade civil e movimentos organizados. ${ }^{20}$ (p. 7)

A aposta em tal estratégia mostra-se coerente com o processo que conduziu a construção da Política Nacional de Gestão Estratégica e Participativa no SUS - ParticipaSUS, cuja origem teve como alguns de seus pilares as deliberações da $12^{\text {a }}$ Conferência Nacional de Saúde, o Plano Nacional de Saúde e as orientações do Conselho Nacional de Saúde, além dos dispositivos constitucionais e legais que regulamentam o SUS ${ }^{21}$.

O ParicipaSUS engloba o:

conjunto de atividades voltadas ao aprimoramento da gestão do SUS, visando maior eficiência, eficácia e efetividade, por meio de ações que incluem o apoio ao controle social, à educação popular, à mobilização social, à busca da equidade, ao monitoramento e avaliação, à ouvidoria, à auditoria e à gestão da ética nos serviços públicos de saúde. ${ }^{21}$ (p. 15)

Intimamente atrelada à concepção de gestão participativa, a educação em saúde é destacada pelo ParticipaSUS, que adverte para o compromisso ético e institucional em prol do resgate da prática educativa como produtora de qualidade de vida. Manifesta-se em todos os atos de promoção, proteção, cuidado e recuperação da saúde, presente desde o cuidado básico ao mais complexo e contempla as dimensões do indivíduo, dos grupos e das comunidades ${ }^{2}$. 
Na dimensão mais geral, a educação em saúde se expressa nas relações sociais como amalgamadora da interação entre os indivíduos, quando da adesão à propostas libertadoras como democracia, participação e direitos de cidadania. É nesta sociedade globalizada que emergem novas referências tais como a solidariedade, o acesso às oportunidades e o direito de ser diferente. Na dimensão particular das políticas de saúde em cada contexto, a proposta de educação em saúde incorpora princípios como intersetorialidade, equidade, participação e controle social, onde suas especificidades decorrem de sua acepção enquanto educação para a cidadania, ou seja, a instrumentalização da sociedade para participar de intervenções na realidade, buscando a qualidade de vida. ${ }^{2}$ (p. 26)

Os esforços empreendidos em direção à participação cidadã e ao controle social são direcionados quase exclusivamente a sua forma institucionalizada, ou seja, aos conselhos de saúde, cuja composição, organização interna, normas de funcionamento e atribuições, foram determinadas pela Lei municipal ${ }^{\circ}$ 6.606/06 e pelo Decreto $n^{\circ} 12.325$, de 29 de junho de 2006.

O Sistema Público Municipal de Saúde estará aberto ao controle da cidadania, representada nos Conselhos de Saúde. Grande prioridade será dada ao fortalecimento do Conselho Municipal e Locais de Saúde, mas envolverá outras ações: a instituição dos Fóruns Regionais de Saúde; o desenvolvimento da ouvidoria de saúde, a colaboração com o Ministério Público para facilitar o exercício de sua função de garantia da relevância pública das ações e serviços de saúde; a oferta, através do Polo de Capacitação Permanente, de um programa de educação continuada dos conselheiros de saúde locais e municipais. ${ }^{20}$ (p. 51)

Essa postura contradiz o que está posto na estratégia de gestão, uma vez que as formas não-institucionalizadas de participação, como os movimentos populares, as organizações nãogovernamentais e as reuniões com a comunidade são pouco valorizadas ou, até mesmo, desqualificadas pela maneira como ocorrem. Um olhar atento e uma escuta aguçada vão apontar que a população participa da construção do sistema de saúde, mesmo que nem sempre de forma organizada, isto é, em espaços instituídos.

Como afirmam Dalbello-Araujo ${ }^{22}$ e Quintanilha ${ }^{23}$, as realidades produzidas pelos usuários trazem inúmeros desconfortos para os serviços e produzem diversas interferências em seu funcionamento, porque sua existência foge à regra e sua presença produz tensão, gera conflito, exige mudança de posturas. Quintanilha ${ }^{23}$ mapeou os jogos de força que perpassam as relações entre profissionais e usuários no cotidiano dos serviços e percebeu que eles se utilizam de diversos meios para anunciarem o que pensam e querem. Por isso, as autoras afirmam que há uma participação que se produz no cotidiano de cada serviço de saúde, não instituída e até mesmo desqualificada.

Nos documentos oficiais e na prática, o que se apresenta é uma espécie de modelo a seguir, destinado àqueles que querem contribuir com o setor saúde. Todavia, espera-se que todas as práticas que não obedeçam a "formalidade" do funcionamento dos conselhos de saúde não sejam reconhecidas como mecanismos legítimos de participação. De modo contrário, podem inclusive ser interpretadas como manifestações sem propósito, perturbadoras da harmonia e do funcionamento dos serviços de saúde.

Conforme salienta Foucault ${ }^{24}$, a perspectiva de se promover a liberdade é própria do liberalismo, ainda que não a aceite. Na medida em que ele fabrica essa liberdade, ocupa-se em manipulá-la a cada instante em nome da segurança da população, garantindo assim a manutenção dos seus interesses.

Logo, os conselhos de saúde simbolizam a materialização dessa liberdade relativa à participação no sistema de saúde e estão ligados diretamente à estrutura hierárquica das secretarias municipais. É justamente esse jogo de liberdade e segurança que se apresenta no reconhecimento dessa forma de participação. Ou seja, aquilo que é passível de controle pelo governo é reconhecido, mas as demais formas de manifestação não são valorizadas.

Esse cerceamento e/ou limitação da participação cidadã e do controle social refletem diretamente sobre as práticas educativas desenvolvidas no SUS. O apoio aos movimentos sociais que se organizam e lutam pelo direito a saúde praticamente inexiste por parte dos serviços de saúde. Uma educação 
em saúde alicerçada pelos valores da Reforma Sanitária precisa estar comprometida com a formação política, quer no âmbito local ou municipal.

Entretanto, o que se percebe nos conselhos de saúde é o predomínio do caráter fiscalizador dessa instância sobre a pedagogia cidadã da participação ${ }^{12}$. Isto é, um espaço que deveria ser referência para a democracia deliberativa, onde toda a população pudesse de fato se manifestar, vem cada vez mais se impregnando da estrutura rígida e morosa que é a máquina burocrática, ficando muito aquém do que poderia contribuir para o desenvolvimento de um sistema de saúde comprometido com as necessidades da população.

\section{Educação em saúde como recurso para vigilância da população}

Ao longo da análise das atas do conselho municipal de saúde, o termo educação em saúde foi mencionado em diversas vezes no período (Tabela 1), merecendo destaque o ano de 2010, no qual o assunto foi citado mais vezes devido aos convites recebidos pelo conselho para a participação em eventos relativos ao tema.

Tabela 1. Número de atas das reuniões do Conselho Municipal de Saúde e citações do termo educação em saúde entre 2005 e 2012.

\begin{tabular}{|c|c|c|c|c|}
\hline \multirow{2}{*}{ Ano } & \multicolumn{2}{|c|}{ Ordinárias } & \multicolumn{2}{|c|}{ Extraordinárias } \\
\hline & $\mathrm{N}^{\circ}$ de atas & $\mathrm{N}^{\circ}$ de citações & $\mathrm{N}^{\circ}$ de atas & $N^{\circ}$ de citações \\
\hline 2005 & 10 & 2 & 7 & 0 \\
\hline 2006 & 12 & 0 & 6 & 2 \\
\hline 2007 & 12 & 1 & 6 & 0 \\
\hline 2008 & 12 & 1 & 4 & 1 \\
\hline 2009 & 12 & 2 & 4 & 2 \\
\hline 2010 & 11 & 7 & 7 & 1 \\
\hline 2011 & 12 & 2 & 9 & 1 \\
\hline 2012 & 10 & 6 & 5 & 2 \\
\hline Total & 91 & 21 & 48 & 8 \\
\hline
\end{tabular}

Entretanto, por se tratar de um conceito polissêmico, há que se considerar o sentido que lhe é atribuído pelos presentes e o lugar que ocupa na pauta de reuniões. Nesse sentido, observou-se que a maioria das menções ao termo educação em saúde, identificada no texto, fazia alusão ao chamado modelo tradicional da educação em saúde ${ }^{4}$.

Esse modo de compreender a práxis educativa se ancora na transmissão de informações, neste caso, informações sobre doenças pautadas no referencial biologicista. O modelo de educação em saúde priorizado nesse contexto é marcado por um discurso higienista e normalizador, em que, por intermédio dos profissionais de saúde, os sujeitos são civilizados e moralizados, são induzidos a adotarem atitudes e comportamentos individuais, supostamente capazes de manter sua saúde. Dessa forma o entendimento sobre educação em saúde se restringe à transmissão de informação. Considera-se, portanto, que o problema é a falta de informação e que, formando multiplicadores, é possível mudar comportamentos.

Conforme assinala Iglesias ${ }^{25}$, os profissionais, munidos dessa convicção, frequentemente utilizam um modelo educativo behaviorista, que entende que cabe a eles ensinar ao usuário o modo ótimo de estar na vida. Nesse contexto, o usuário é envolvido no cumprimento das determinações e como propagador das informações passadas pelos profissionais de saúde, como "multiplicadores".

As referências à educação em saúde presentes nas atas das reuniões do Conselho Municipal mencionam um entendimento que se caracteriza pela normativa das ações e pela transmissão vertical das informações, no qual o saber técnico sobrepõe-se ao saber popular ${ }^{8}$. Além disso, traz o pressuposto de que a prevenção das doenças deriva da mudança de atitude e dos comportamentos individuais. 
Esse modelo de ação educativa vai ao encontro daquilo que Foucault ${ }^{26}$ convencionou chamar de normalização disciplinar. O mecanismo consiste em colocar um modelo ótimo, cujo arcabouço é estruturado em função de certo resultado. Logo, "procura tomar as pessoas, os gestos, os atos, conforme a esse modelo, sendo normal precisamente quem é capaz de se conformar a essa norma e o anormal quem não é capaz" 26 .

O conselheiro [...] lembrou que é importante a educação da comunidade para criação de bons hábitos. ${ }^{27}$ (p. 3)

Apresentou a proposta dos indicadores para os anos de 2010-2011 [...] realizar atividade educativa sobre a temática nutricional com relação ao consumo de sódio, açúcar, gordura, para o setor produtivo e população - a meta para 2010-1011 é desenvolver um programa de educação sanitária. ${ }^{28}$ (p. 2)

Essa concepção hegemônica de educação em saúde esteve presente desde o início da primeira gestão, mantendo sua frequência ao longo dos dois governos. Surge geralmente como pauta nas reuniões, tanto das ordinárias quanto das extraordinárias. Entretanto, embora sua importância seja ressaltada, sua menção ocorre pontualmente, com pouco conteúdo e sem qualquer debate ou reflexão acerca de sua operacionalização.

Outra questão pertinente diz respeito ao atrelamento das ações educativas aos programas de saúde e/ou agravos específicos. São comuns algumas menções como:

Disse que estão implementando as ações de educação em saúde sobre a tuberculose nas Unidades de Saúde. ${ }^{29}$ (p. 2)

A conselheira [...] acredita que as ações educativas são de grande importância para a população na prevenção da dengue..$^{30}$ (p. 1)

Falou que o Plano de Ações e Metas para DST/AIDS está dividido em 3 eixos temáticos: Promoção; Diagnóstico, Tratamento e Assistência; Gestão e Desenvolvimento Humano e Institucional. No ponto de promoção destacam-se: elaboração de material gráfico educativo para três populações..$^{31}$ (p. 2)

Embora as ações do Ministério da Saúde para a atenção básica preconizem, entre outros, a participação popular, o controle social e o reconhecimento da saúde como direito de cidadania, tornase evidente a perpetuação de práticas assistencialistas, compartimentalizadas e medicalizantes nos serviços de saúde.

Conforme advertem Albuquerque e Stotz ${ }^{3}$, essas atividades de educação em saúde são geralmente realizadas conforme o programa da ocasião ou a epidemia em curso no momento. Logo, não há uma preocupação com a continuidade das ações, tampouco com a integralidade dos processos.

Outra questão que cabe ressaltar é que grande parte das ações propostas para a educação em saúde possui como cenário de desenvolvimento o ambiente escolar.

O conselheiro [...] falou da importância da educação em saúde ensinada nas escolas e veiculada na mídia. $^{32}$ (p. 3)

A Dra . [...] apresentou dados epidemiológicos relativos à AIDS no município de Vitória. Em sua apresentação falou que na área de promoção à saúde é proposto a produção de material informativo para a população, além de palestras educativas na rede educacional do município. ${ }^{33}$ (p. 3)

[...] as propostas para o programa (Saúde Escolar) são: [...] ações de promoção da saúde e prevenção de doenças: educação para a saúde sexual, saúde reprodutiva, cultura da paz e prevenção das DST/ AIDS, uso indevido de drogas e violências. ${ }^{34}$ (p. 1) 
Em relação ao privilégio da infância e da medicalização da família, Foucault ${ }^{35}$ afirma que "não se trata, apenas, de produzir um melhor número de crianças, mas de gerir convenientemente esta época da vida". Percebe-se, na análise dos documentos, que a escola continua sendo considerada como o espaço da educação por excelência, ou seja, o local onde se normatiza a infância, com o objetivo de viabilizar as condições necessárias para garantir a sobrevivência das crianças, a fim de que o seu desenvolvimento se torne útil para a sociedade.

Ao contrário do discurso pautado no que diz respeito à cidadania e no desenvolvimento da autonomia dos sujeitos, essa concepção de educação formal, ou seja, gerida no ambiente escolar e que almeja reger o modo de ser e viver dos indivíduos adquire contornos de vigilância. Ao se propor a disciplinar os corpos, coloca-os diante a conformidade da regra e submetem-nos "a uma perpétua pirâmide de olhares" ${ }^{35}$ (p. 106).

A administração municipal espera reproduzir práticas de educação em saúde dentro do ambiente escolar, reforçando que a relação ensino-aprendizagem se dá, por excelência, nos espaços formais e instituídos da educação. A escola passa assim a representar o lócus do ensino em saúde. Daí, então, que as práticas esperadas pelo município também se balizam por uma experiência professoral, pautada na transmissão de conhecimentos considerados "corretos", destinados a crianças que deverão "aprender" e consumir o discurso da saúde de forma normativa.

Desse modo, a educação em saúde segue impregnada por sua concepção tradicional, sendo estrategicamente utilizada como mecanismo de controle da sociedade. Torna-se, sobretudo, endereçada às populações mais pobres, com o objetivo de garantir manutenção da força de trabalho e a proteção contra os perigos gerais causados, interesse último das classes políticas e econômicas com maior poder aquisitivo.

\section{Educação Popular em Saúde na gestão municipal: estratégia de gestão participativa ou nova forma de controle?}

Mesmo com a orientação do Ministério da Saúde de fortalecer os processos que envolvem o desenvolvimento do controle social e das práticas de educação em saúde em perspectiva dialógica nos serviços, por intermédio da criação da Secretaria de Gestão Estratégica e Participativa em 2005, embasada pelos pressupostos da Educação Popular, a Semus não pautou essa questão ao longo da primeira gestão de governo em análise.

Embora a maioria das menções relativas a educação em saúde, presentes nas atas ordinárias e extraordinárias do Conselho Municipal de Saúde, façam alusão a ações pontuais e direcionadas a programas e/ou agravos específicos, constatou-se a presença de algumas inserções da temática da Educação Popular em Saúde a partir de 2009, ano de início da segunda gestão.

Segundo Vasconcelos ${ }^{36}$, a Educação Popular tem por finalidade trabalhar pedagogicamente 0 homem e os grupos envolvidos no processo de participação popular, de modo a desenvolver estratégias coletivas de aprendizado e investigação, cujo objetivo seria promover o crescimento da capacidade de análise crítica sobre a realidade e o aperfeiçoamento das estratégias de luta e enfrentamento. Configura-se, portanto, em uma maneira de construção da participação popular no redirecionamento da vida social.

Inicialmente, o tema Educação Popular em Saúde figurou na pauta de uma reunião extraordinária por intermédio de um convite recebido pelo Conselho Municipal de Saúde, solicitando o envio de representantes para um congresso, onde o assunto seria discutido.

O Secretário Executivo informou que o Conselho Municipal de Saúde recebeu um convite para participar do $8^{\circ}$ Congresso Nacional da Rede Unida [...]. A SEMUS participará com um representante da gestão. Falou que a temática é educação, trabalho e cidadania. Uma das discussões centrais é o debate sobre educação popular. Falou da importância de discutir a implantação da educação popular pela Secretaria Municipal de Saúde. Sugeriu um membro para participar do congresso para se apropriar desta discussão e que no retorno possa começar a discutir ações para a política de educação popular. ${ }^{31}$ (p. 3) 
Posteriormente, esse assunto voltou a ser mencionado em duas ocasiões no ano de 2010. Em ambas as oportunidades, o tema novamente foi colocado em pauta mediante o recebimento de convites para a participação em eventos, a saber: o Encontro Regional de Educação Popular em Saúde e o III Encontro Nacional da Articulação Nacional de Educação Popular em Saúde (Aneps). Nesse sentido, tal qual a representação do Conselho Municipal nos eventos, o repasse das informações dos congressos ao conselho também é de fundamental importância. No entanto, quando ocorre, é de modo muito frágil.

Mesmo que o plano de governo da segunda gestão tenha se comprometido em "promover espaços de participação e articulação dos profissionais com os movimentos de educação popular em saúde" 37 (p. 100), o que se constatou, nas atas do Conselho Municipal, foram apenas menções pontuais ao termo, que não alcançaram a profundidade necessária. Sem debater a questão com maior amplitude, despreza-se a oportunidade de refletir sobre o reconhecimento, a importância e, sobretudo, o desenvolvimento de práticas educativas orientadas pelos princípios da Educação Popular em Saúde, desvirtuando seu sentido.

A aposta teórica e prática da Educação Popular visa superar o próprio setor saúde ao propor a formação crítica dos representantes da sociedade civil de caráter popular, no sentido de ampliar a consciência e compreensão das condições de vida, bem como as relações existentes com a saúde, configurando-se em esteio para os movimentos e lutas em defesa da qualidade de vida, cidadania e controle social ${ }^{38}$.

Passados dois anos sem citação nas atas das reuniões do Conselho Municipal de Vitória, o tema foi retomado, em 2012, em algumas oportunidades. Primeiramente, surge como tema do ciclo de palestras promovido pela Escola Técnica do SUS - ETSUS, que convida os conselheiros municipais para o evento. Logo após, surge o convite e a indicação dos membros do conselho para o Encontro Nacional de Educação Popular em Saúde (Eneps), cujo tema foi "Educação popular como estratégia de controle social no SUS". Durante o repasse das informações sobre o evento na reunião seguinte, os representantes afirmaram que o Eneps "foi muito rico e permitiu a convivência com parteiras, umbandistas, benzedeiras, ou seja, uma riqueza de Brasil" 39 (p. 4).

Ainda que timidamente e aproximando-se do final do mandato da gestão 2009-2012, o Conselho Municipal de Saúde

sugeriu a constituição de um comitê estadual de educação popular sediado e mantido pelo Conselho Municipal de Saúde de Vitória. A intenção é organizar e ter um espaço de diálogo e discussão sobre todas as iniciativas de educação popular em saúde no município. A ideia é que o comitê organize essas atividades e amplie esse movimento. O presidente sugeriu a realização do encontro municipal de educação popular em dezembro, onde poderia ser criado o comitê. ${ }^{40}$ (p. 5)

Nesse processo que conduziu a realização do I Encontro de Educação Popular em Saúde de Vitória, algumas inquietações figuram como objeto de reflexão: Por que fomentar um encontro dessa natureza apenas no final da gestão, ainda que o tema estivesse pautado desde o início no Plano Municipal de Saúde? Qual a motivação do Conselho Municipal de Saúde em propor um evento que não constava em sua programação anual e que ocorreu de maneira tão rápida entre sua concepção e realização? Como esse comitê poderá ser de fato um espaço de diálogo, troca de experiência, respeito à cultura popular e de gestão participativa se, diferentemente de outras experiências do país, ele não foi concebido nos movimentos populares de saúde, pois já nasce institucionalizado, ou seja, está ligado aos interesses da máquina administrativa? Como ampliar o debate sobre a Educação Popular para além do comitê, de modo a envolver todos os trabalhadores dos serviços de saúde da Semus?

Torna-se evidente, portanto, que não se trata apenas de caracterizar a Educação Popular em Saúde como uma realidade na capital capixaba. Para que se torne de fato uma estratégia de gestão participativa ${ }^{41}$, é preciso, anteriormente, ter o zelo necessário de apresentar a lógica de seus pressupostos, tanto para os conselheiros de saúde quanto para os trabalhadores, gestores, instituições de ensino e, sobretudo, para a população.

Outra análise refere-se à organização do processo de trabalho, que caracterizou a educação em saúde como uma ação de "vigilância" no período de 2005 a 2012. Esse deslocamento feito pela 
Secretaria Municipal de Saúde implica na realização de uma ação, mensurada a partir de indicadores estatísticos: índices, metas, número de ações, entre outros.

Do ponto de vista no qual se entende a educação em saúde como uma prática dialógica, é possível inferir que a ação deverá ser cobrada como um número (ou indicador) e não por meio de uma perspectiva que vise ao encontro de pessoas, suas histórias e experiências. Quando a educação em saúde se torna um indicador a ser perseguido pela vigilância, retira-se a perspectiva dialógica e qualitativa da ação e insere-se a perspectiva numérica e quantitativa das metas a serem alcançadas pela administração municipal.

Esse deslocamento, proposto na organização do trabalho da Secretaria Municipal, irá implicar diretamente o debate no Conselho de Saúde. Uma vez que a educação em saúde se torne uma ação "de vigilância", o conselho deverá se posicionar sobre ela com o papel fiscalizador, esvaziando, ainda mais, o caráter político de discussão e debate sobre as práticas político-pedagógicas de educação em saúde com caráter de Educação Popular.

A estratégia de deslocar a educação em saúde para uma área organizacional da vigilância parece algo que pertence somente a um novo arranjo da organização do processo de trabalho. No entanto, entende-se que essa estratégia sugere a ratificação de um processo que já vinha há tempos se projetando para tal: a) organiza-se a educação em saúde por doenças ou agravos; b) considera-se somente as práticas produzidas nos espaços formais da educação (unidades de saúde e escolas) e, por último; c) organizam-se ações a partir de indicadores numéricos a serem fiscalizados pela vigilância.

Essa estratégia biopolítica de transformar em "processos" práticas que se davam em uma relação "inteira" com seres humanos, acabam por transformar a educação em saúde em algo esvaziado de sentido pelos trabalhadores do SUS, uma vez que a prática se torna uma série de "procedimentos" a serem acompanhados de forma processual. E, ainda, dos conselhos de saúde será pautada uma agenda fragmentada, desvinculada de lutas políticas maiores ou como se não pertencessem a uma dimensão maior de trabalhar em prol da saúde como uma militância política que defende a vida.

Quem perde com isso são os usuários do sistema público de saúde, que, cada vez mais, demandam informações e diálogo como uma boa prática e exercício de democracia no sistema de saúde brasileiro.

\section{Conclusões}

Os documentos oficiais, produzidos entre 2005 a 2012, evidenciaram a opção da política municipal pela construção de uma gestão participativa e democrática, acompanhando as diretrizes do Ministério da Saúde expressas em políticas como o ParticipaSUS.

Embora estivessem resumidas, as atas das reuniões do Conselho de Saúde analisadas apresentaram boa organização em sua estrutura. Os pontos de pauta estavam separados dos informes e os autores das principais falas estavam identificados, possibilitando que esses documentos fossem eleitos como fonte de dados para esta pesquisa. Cabe ressaltar que não houve qualquer constrangimento ou dificuldade de acesso ao material e que as atas mais recentes estão disponíveis por meio eletrônico na internet.

Assim, observou-se que, cada vez mais o Conselho de Saúde se torna parte da engenharia política da máquina administrativa, corroborando com Vasconcelos ${ }^{42}$ quando afirma que essa estrutura juntamente com as conferências de saúde têm se empenhado, sobretudo, a temas relativos à gestão e ao planejamento das políticas de saúde. Não contempla a articulação e o apoio às práticas em uma perspectiva dialógica e participativa de enfrentamento das necessidades de saúde na sociedade.

A principal concepção de educação em saúde que emana das atas se orienta pelo modelo hegemônico, tradicional, caracterizado pelo emprego de ações pontuais, verticalizadas e ancoradas no saber técnico. Esse entendimento das práticas educativas não favorece a autonomia e o respeito à subjetividade dos sujeitos. Configura-se, portanto, como estratégia de vigilância de Estado, uma vez que disciplina os corpos individuais, impondo-lhes um "modelo correto" a ser seguido, traduzido pela "indiscutível" adoção do hábito saudável de vida.

Somente durante a segunda gestão, outra concepção de ação educativa foi mencionada nos debates do Conselho Municipal. A Educação Popular em Saúde, orientada pelo processo dialógico, 
figura esporádicas vezes, geralmente de modo pontual e ligada a convites a participação em eventos da área. No fim do último ano de governo, é proposta a criação do Comitê de Educação Popular em Saúde e a realização do I Encontro Municipal de Educação Popular em Saúde de Vitória, sem que houvesse maior amplitude na discussão sobre o assunto.

Nesse sentido, ampliar e reconhecer as diferentes formas de participação e controle social no município de Vitória faz-se necessário para o fortalecimento do sistema de saúde local. Além disso, é preciso ampliar o debate acerca do modelo dialógico da educação em saúde, referenciado no ParticipaSUS pelos pressupostos da Educação Popular, de modo a promover um sistema mais justo, equânime, participativo e em sintonia com as reais necessidades da população.

Por ora, cabe ainda considerar que o deslocamento das ações de educação em saúde para a vigilância posiciona o debate sobre o tema dentro dos conselhos como algo que deve ser regulado ou fiscalizado. Perde-se a dimensão que a participação popular é algo que dá a diretriz na gestão social da política pública e sugere uma proposta política de controle ou unicamente "monitoramento" do cumprimento ou não da prática em si. Isso esvazia o caráter de qualificar a política pública que o Conselho de Saúde tem, transferindo até mesmo as práticas mais fundamentadas nas relações humanas para números a serem quantificados, cabendo ao conselho conferir se a meta foi alcançada dentro de indicadores preestabelecidos, o que caracteriza um conselho de saúde como "externo", "exógeno" à criação e a gestão das políticas públicas de saúde.

\section{Colaboradores}

Welington Serra Lazarini foi responsável pela concepção, análise e escrita do artigo. Francis Sodré participou como orientadora da pesquisa. Maristela Dalbello-Araújo contribuiu fortemente com a revisão final do texto.

\section{Referências}

1. Côrtes SMV. Conselhos e Conferências de Saúde: papel institucional e mudanças nas relações entre Estado e sociedade. In: Fleury S, Lobato LVC, organizadores. Participação, democracia e saúde. Rio de Janeiro: CEBES; 2010. p. 102-28.

2. Ministério da Saúde. Secretaria de Gestão Estratégica e Participativa. Departamento de Apoio a Gestão Participativa. Oficina Nacional de Educação em Saúde nos Serviços do SUS: Síntese do Relatório. Brasília (DF): MS; 2008.

3. Albuquerque PC, Stotz EN. A educação popular na atenção básica à saúde no município: em busca da integralidade. Interface (Botucatu). 2004; 8(15):259-74.

4. Alves VS. Um modelo de educação em saúde para o Programa Saúde da Família: pela integralidade da atenção e reorientação do modelo assistencial. Interface (Botucatu). 2005; 9(16):39-52.

5. Besen CB, Souza Netto MS, Da Ros MA, Silva FW, Silva CG, Peres MF. A estratégia saúde da família como objeto de educação em saúde. Saude Soc. 2007; 16(1):57-68.

6. Silva CMC, Meneghim MC, Pereira AC, Malhe FL. Educação em saúde: uma reflexão histórica de suas práticas. Cienc Saude Colet. 2010; 15(5):2539-50.

7. Schall VT, Stuchiner M. Educação em saúde: novas perspectivas [editorial]. Cad Saude Publica. 1999; 15(2):4-5.

8. Vasconcelos EM. Educação popular e a atenção à saúde da família. São Paulo: Hucitec; 1999.

9. Pedrosa JI S. Educação Popular, saúde, institucionalização: temas para debate. Interface (Botucatu). 2001; 5(8):137-8. 
10. Oliveira LC, Pinheiro R. A participação nos conselhos de saúde e sua interface com a cultura política. Cienc Saude Colet. 2010; 15(5):2455-64.

11. Labra ME. Conselhos de Saúde: dilemas, avanços e desafios. In: Lima NT, Gerschman S, Edler FC, Manuel Suárez J, organizadores. Saúde e democracia: história e perspectivas do SUS. Rio de Janeiro: Fiocruz; 2006. p. 353-83.

12. Escorel S, Moreira MR. Desafios da participação social em saúde na nova agenda da reforma sanitária: democracia deliberativa e efetividade. In: Fleury S, Lobato LVC, organizadores. Participação, democracia e saúde. Rio de Janeiro: Cebes; 2010. p. 229-47.

13. Minayo MC. O desafio do conhecimento: pesquisa qualitativa em saúde. 9a ed. São Paulo: Hucitec; 2006.

14. Prefeitura Municipal de Vitória. Secretaria de Saúde. Relatório de gestão 2009 [Internet]. Vitória; 2010 [acesso 2011 Jul 11]. Disponível em: http://www.vitoria.es.gov. br/arquivos/20100519_saude_relator_gestao_2009.pdf

15. Lüdke $M$, André MEDA. Métodos de coleta de dados: observação, entrevista e análise documental. In: Lüdke $M$, André MEDA, organizadores. Pesquisa em educação: abordagens qualitativas. São Paulo: EPU; 1986. p. 25-44. cap. 3.

16. Bardin L. Análise de conteúdo. Lisboa: Edições 70; 1988.

17. Oliveira DC. Análise de conteúdo temático-categorial: uma proposta de sistematização. Rev Enferm UERJ. 2008; 16(4):569-76.

18. Bauer MW. Análise de conteúdo clássica: uma revisão. In: Bauer MW, Gaskell G, organizadores. Pesquisa qualitativa com texto: imagem e som. Petrópolis: Vozes; 2002. p. $189-221$.

19. Foucault M. Em defesa da sociedade: curso no Collège de France, 1975-1976. São Paulo: Martins Fontes; 2002.

20. Prefeitura Municipal de Vitória. Secretaria de Saúde. Plano Municipal De Saúde 20062009 [Internet]. Vitória; 2005 [acesso 2011 Jul 11]. Disponível em: http://www.vitoria. es.gov.br/arquivos/20100519_saude_plano_2006_2009.pdf

21. Ministério da Saúde. Secretaria de Gestão Estratégica e Participativa. Política Nacional de Gestão Estratégica e Participativa no SUS - ParticipaSUS. 2a ed. Brasília (DF): MS; 2009.

22. Dalbello-Araújo M. O cotidiano de uma equipe do Programa de Saúde da Família: um olhar genealógico sobre o controle social [tese]. Vitória (ES): Programa de Pós-Graduação em Psicologia, Universidade Federal do Espírito Santo; 2005.

23. Quintanilha BC. Participação rizomática: um modo de participação social no sistema Único de Saúde [dissertação]. Vitória (ES): Programa de Pós-Graduação em Saúde Coletiva, Universidade Federal do Espírito Santo; 2012.

24. Foucault M. O nascimento da Biopolítica: curso no Collège de France, 1977-1978. São Paulo: Martins Fontes; 2008.

25. Iglesias A. Em nome da Promoção à Saúde: análise das ações em macrorregião do município de Vitória-ES [dissertação]. Vitória (ES): Programa de Pós-Graduação em Saúde Coletiva, Universidade Federal do Espírito Santo; 2009.

26. Foucault M. Segurança, território, população: curso no Collège de France, 1977-1978. São Paulo: Martins Fontes; 2008.

27. Conselho Municipal de Saúde de Vitória. Secretaria de Saúde. Ata da $66^{a}$ reunião ordinária realizada no dia 09 de setembro. Vitória; 2010.

28. Conselho Municipal de Saúde de Vitória. Secretaria de Saúde. Ata da $60^{a}$ reunião ordinária realizada no dia 11 de março. Vitória; 2010. 
29. Conselho Municipal de Saúde de Vitória. Ata da $47^{a}$ reunião ordinária realizada no dia 08 de janeiro. Vitória; 2009.

30. Conselho Municipal de Saúde de Vitória. Ata da $27^{a}$ reunião extraordinária realizada no dia 17 de abril. Vitória; 2009.

31. Conselho Municipal de Saúde de Vitória. Ata da $45^{a}$ reunião ordinária realizada no dia 13 de novembro. Vitória; 2008.

32. Conselho Municipal de Saúde de Vitória. Secretaria de Saúde. Ata da $62^{a}$ reunião ordinária realizada no dia 13 de maio. Vitória; 2010.

33. Conselho Municipal de Saúde de Vitória. Ata da $32^{a}$ reunião ordinária realizada no dia 11 de outubro. Vitória; 2007.

34. Conselho Municipal de Saúde de Vitória. Ata da $26^{a}$ reunião extraordinária realizada no dia 25 de novembro. Vitória; 2008.

35. Foucault M. Microfísica do poder. 8a ed. Rio de Janeiro: Graal; 1979.

36. Vasconcelos EM. Educação popular: de uma prática alternativa a uma estratégia de gestão participativa das políticas de saúde. Physis. 2004; 14(1):67-83.

37. Prefeitura Municipal de Vitória. Secretaria de Saúde. Plano Municipal De Saúde 20102013 [Internet]. Vitória; 2009 [acesso 2011 Jul 11]. Disponível em: http://www.vitoria. es.gov.br/arquivos/20100519_saude_plano_2010_2013.pdf

38. Valla VV, Stotz EN. Apresentação. In: Valla VV, Stotz EN, organizadores. Participação popular, educação e saúde: teoria e prática. Rio de Janeiro: Relume-Dumará; 1993. p. 7-8.

39. Conselho Municipal de Saúde de Vitória. Ata da 89a reunião ordinária realizada no dia 16 de agosto. Vitória; 2012.

40. Conselho Municipal de Saúde de Vitória. Ata da 51ª reunião extraordinária realizada no dia 25 de setembro. Vitória; 2012.

41. Pedrosa JI S. Educação Popular em saúde e gestão participativa no Sistema Único de Saúde. Rev APS. 2008; 11(3):303-13.

42. Vasconcelos EM. Para além do controle social: a insistência dos movimentos sociais em investir na redefinição das práticas de saúde. In: Fleury S, Lobato L VC. Participação, democracia e saúde. Rio de Janeiro: Cebes; 2010. p. 270-88.

Lazarini WS, Sodré F, Dalbello-Araujo M. El debate sobre educación en salud en el ámbito del Consejo Municipal de Salud de Vitória, Espírito Santo, Brasil. Interface (Botucatu). 2014;18 Supl 2:1227-1240.

Se analizó la relación entre educación en salud y la política de participación de control social en salud de la Secretaría Municipal de Salud de Vitória, Espírito Santo, Brasil entre 2005 y 2012. Se realizó un análisis documentario en los ámbitos municipales de salud, informes de gestión y en 139 actas del Consejo Municipal de Salud. Quedó claro que la gestión orientó su política por la participación, pero se limitó al Consejo Municipal de Salud. La educación en salud se trató puntualmente durante las reuniones. Al ser debatida, se consideró como modelo tradicional, configurándose en estrategia para vigilancia. La educación popular en salud se mencionó en el segundo gobierno, pero sin redefinición de las prácticas. Se muestra la necesidad de reconocer las diferentes formas de participación social y ampliación del debate sobre el modelo dialógico de la educación en salud.

Palabras clave: Educación en salud. Participación social. Consejo de Salud. 
